\title{
Kamu Politikalarında Şeffaflık ve Açıklık İlkelerine E-Katılımın Etkisi
}

\author{
The Influence of E-participation on Transparency and Openness Principles in Public Policy
}

\section{Dilek DEDE}

Dr. Arş. Gör., İstanbul Üniversitesi, SBF,

Siyaset Bilimi ve Kamu Yönetimi Bölümü,

dilekdede@istanbul.edu.tr

https://orcid.org/0000-0002-8686-6870
Makale Başvuru Tarihi: 21.09.2021

Makale Kabul Tarihi: 24.12.2021

Makale Türü: Araştırma Makalesi
Anahtar Kelimeler:

Açık Kamu

Politikalarl,

Şeffaflı ve Açılklk

Ilkesi,

Sivil Katılım

Süreçleri,

Bilgi Teknolojileri,

E-Katılım,

\section{ÖZET}

Bu çalışma kamu politikalarında şeffaflık ve açıklık ilkelerine e-katılımın etkilerini araştırmaya odaklanmaktadır. Çalışmanın araştırma soruları şunlardır; "Şeffaflık ve açılklk ilkelerinin açılanma biçimindeki değişim nasıl açıklanabilir?" ve "kamu politikaları çalışmalarında bu ilkelerin açıklanmasında e-katılımın etkisi nedir?" Alan-yazın taramasında kamu politikaları çalışmalarında şeffaflık ve açıklık ilkelerinin iki açıdan incelenebileceği görülmektedir. Kamu politikalarında şeffaflık ve açılık ilkelerini ekatılımın etkileriyle açıklayan çalışmalar, tarafların karar almanın konusunu oluşturan siyasaya ilişsin tüm bilgilerin karar alma sürecinde yer alan taraflara aktarılmast, bilgiye erişim ve sivil katılım süreçleri üzerinedir. İkinci tür çalışmalar şeffaflık ve açıklık ilkeleri ile "vatandaşlar için ortak refah" ilişkisi konusuna odaklanmaktadır. Bu çalışma birinci tür çalışmalara odaklanan yöntemsel olarak teorik, açılayıcı bir çalışmadır. Çalışma üç bölüm olarak tasarlanmıştır. Illk olarak şeffaflık ve açıklık ilkelerinin tanımlarına ve bu ilkelerin son dönemde e-katılımın yükselişsi ile değişen anlamına işaret edilmektedir. İkinci bölümde ekatılımın kavramsal değerlendirmesi yapılmaktadır. Son bölümde kamu politikaları çalışmalarında şeffaflı ve açıklık ilkelerine e-katılımın etkisi değerlendirilmektedir.
Keywords:

Open Public Policy,

Transparency and Openness Principle,

Civil Participation Processes,

Information Technologies,

E-Participation,

\section{ABSTRACT}

This study focuses on investigating the principles of transparency and openness in public policy with the influence of participation. The study's research questions are as follows: "How can the changing meaning of openness and transparency principles be explained?" "What extent has the e-participation influenced to explain these principles in public policy studies?" It can be seen that the principles of transparency and openness in the study of public policy in the literature can be examined in two veins. The studies explain the principles of transparency and openness in public policies with the influence of e-participation, the process of transferring all information about the politics of decision-making to the parties involved in the decisionmaking process, access to information, and civic participation processes. The second type of work focuses on transparency and openness principles and on the relationship of "collective welfare for citizens". This study is concerned with first type studies, a theoretical, explanatory work. The study is designed in three parts. First, the definition of transparency and openness principles and the changing meaning of these principles with the recent rise of e-participation have been pointed out. Second, the conceptual background of eparticipation has been evaluated. Finally, the impacts of e-participation on the principles of transparency and openness in public policy studies have been assessed. 


\section{GIRISS}

Şeffaflık ve açıklık ilkeleri, kamu politikaları döngüsünün bir unsuru olan karar alma sürecinde yer alan taraflardan biri olan idarenin tanımlanmasında kullanılmaktadır. Güran (1982:102), yönetimin açıklığı kavramını; idarenin "tek yanlı" karar alma yetkisini kullanırken "kapalılığın aralanması", karar alma sürecinin saydamlığa kavuşturulması olarak tanımlar. Duran (1998:29)'a göre şeffaflık ve açıklık; karar alma sürecinde kullanılan bilgi ve belgelerin ilgililerin erişimine açılması olarak tanımlamaktadır. Eryılmaz'a (1993:106) göre açıklık, idarenin otoriter tutumunun ve sınırlı katılımın azaltılarak halkın etkilerine açı bir yönetimin inşa edilmesidir. Başka bir tanımda Eken (1994:39) "şeffaf yönetim”, (Duran, 1998) “açıklık”, (Özay, 2002) "günışı̆̆ında yönetim" kavramları ile tanımlanan yönetim biçimini; gizli ve dışa kapalı yönetim sistemine alternatif bir model olarak açıklar. Bu modelde yönetim ve toplum arasındaki mesafenin azaltılarak yönetimin toplumsal duyarlılığının arttırılması amaçlandığı görülür. (Eken, 2005:116).

Eryılmaz'a (1993:102) göre açıklık ilkesinin amacı, idarenin otoriter tutumunu ve karar alma sürecine sınırlı katılımı azaltarak halkın etkilerine açık bir yönetimi inşa etmektir. Bu ilke sadece karar alma sürecinde tarafların bilgilendirilmesinden ibaret değildir. Karar alma süreci sonrası alınan kararlardan ilgili kişileri haberdar etmeyi de kapsamaktadır. Böylece kişiler isterlerse açıklık ilkesinden yararlanarak haklarında alınan kararları değiştirme imkânına da kavuşmuş olacaklardır. Bu tanımlar yönetim bilimi ve siyaset bilimi kavramlarından hareketle oluşturulmuştur.

Bu tanımlara ek olarak "şeffaflık" ve "açıklık" ilkeleri maliye disiplini içinde de tanımlanmaktadır. Açıklık ilkesi, maliye disiplini içinde satın alımlarla ve bütçeyle ilgili olarak tanımlanmaktadır. Parlak’a (2011:3) göre satın almalarla ilgili olarak açıklık ilkesi; ihaleye katılan ya da ihaleyle ilgili olan herkesin ihale hakkında bilgi sahibi olması için, ihale bilgilerinin görsel ve işitsel araçlar kullanılarak ilan edilmesi ve duyurulmasını ifade eder. Bütçeyle bağlantılı olarak açıklık ilkesi; kamu hizmetlerinin en etkili ve verimli bir şekilde gerçekleştirilmesi için kaynak kullanımı ve kamu finansmanını düzenleyen bir araç olarak bütçenin herkes tarafindan kolaylıkla anlaşılabilir olmasını ifade eder.

Şeffaflık ve açıklık ilkeleri, kamu politikaları çalışmalarında açık kamu politikaları (open public policy) olarak adlandırılmaktadır. Açık kamu politikaları, siyasa-yapımı sürecini oluşturan önemli politika kararları ve eylemlerinde yer alan tüm taraflar için şeffaflığın olduğu bir süreç olarak tanımlanır (Bertot vd., 2010; Meijer, 2013).

E-katılım kavramı ise bilgi ve iletişim teknolojilerindeki gelişmelerin siyaset bilimi ve yönetim bilimi alanlarına etkisi sonrası, geleneksel "katılım" kavramının yeni bir formu olarak ele alınabilir. Akademik çalışmalarda ekatılım kavramı basitçe vatandaşların bilgi ve iletişim teknolojileri araçlarıyla karar alma aşamalarına ve kamu hizmetleri erişiminin sağlanması olarak tanımlanmaktadır. (Macintosh, 2004; Saebø vd., 2008, Medaglia, 2012). Diğer bir tanımlama biçimi ise politika yapımı sürecinin tasarımı, karar alma süreçleri ve karar süreçlerinin izlenmesi kapsamında ele alınmaktadır. Ayrıca, e-katılım kavramı; e-demokrasi ve e-devlet kavramları ile bağlantılı olarak açıklanmaktadır (Welch, 2012).

Alan-yazın taramasında kamu politikalarında şeffaflık ve açıklık ilkelerinin e-katılım ile ilişkisinin iki açıdan incelendiği görülmektedir. Kamu politikalarında şeffaflık ve açıklık ilkeleri ile e-katılımın ilişkisini açıklayan çalışmalar ve şeffaflık ve açıklık ilkelerini kollektif refah ilişkisi ile açıklayan çalışmalar. İlk tür çalışmalar; karar alma sürecine ilişkin tüm bilgilerin süreçte yer alan taraflara aktarılması; bilgiye erişim ve sivil katılım süreçleri (Harrison ve Sayogo, 2014; Irani vd., 2008; Larsson ve Grönlund, 2014) üzerinedir. İkinci tür çalışmalar ise şeffaflık ve açıklık ilkeleri ile "vatandaşlar için kolektif refah" (Lee ve Kwak, 2012; Noveck, 2015; Brunswicker vd., 2018) ilişkisine odaklanır. Bu çalışma; kamu politikalarında şeffaflık ve açıklık ilkelerini e-katılımın etkileriyle açıklayan ilk tür çalışmalara odaklanmaktadır. Çalışmanın araştırma soruları şunlardır;

- Kamu politikaları çalışmalarında bu ilkelerin açıklanma biçimindeki değişim nasıl açıklanabilir?

- Kamu politikaları çalışmalarında bu ilkelerin açıklanmasında e-katılımın etkisi nedir?

Çalışma yöntemsel olarak teorik, açıklayıcı bir çalışmadır. Kamu politikalarında şeffaflık ve açıklık ilkelerinin, dijital olanakların gelişmesi ile yaygınlaşan e-katılımın etkisi ile söz konusu ilkelerin değişen anlamlarını tespit etmekte ve açıklamaktadır. Çalışma üç bölüm olarak tasarlanmıştır. İlk olarak şeffaflık ve açıklık ilkelerinin kavramsal boyutu ele alınmıştır. İkinci bölümde e-katılımın kavramsal değerlendirmesi yapılmaktadır. 
Son bölümde; kamu politikaları çalışmalarında şeffaflık ve açıklık ilkelerini e-katılım etkileriyle açıklayan çalışmalara yer verilerek, değerlendirmelerde bulunulmuştur. Şeffaflık ve açıklık ilkeleriyle ilgili kavramsal çerçeve oluşturulurken hem alan yazındaki çalışmalar hem de ulus-üstü kurumların raporlarındaki tanımlardan yararlanılmıştır. Bu çalışmada kamu politikalarında şeffaflık ve açıklık ilkelerinin kavramsal içeriklerinin ve anlamlarının süreç içinde değişime uğradığı iddia edilmektedir. Bu temel savı destekleyecek şekilde, alanyazında ve raporlarda kamu politikalarında şeffaflık ve açıklık ilkelerinin tanımlarının üç farklı eğilimi yansıttığı belirlenmiştir. Kamu politikalarında şeffaflık ve açıklık ilkelerinin e-katılım ile ilişkisi sonuç bölümünde açıklanmıştır.

\section{2. ŞEFFAFLIK VE AÇIKLIK ILKELERININN KAVRAMSAL AÇIDAN DEĞERLENDİRILMESİ}

Şeffaflık ve açıklık ilkleri, alan yazında çeşitli disiplinler kapsamında değerlendirilmektedir. Bu ilkelerin açıklandığı başlıca disiplinler yönetim bilimleri, siyaset bilimi, kamu yönetimi, maliyedir. Belirtilen disiplinlerde yer alan açılık ve şeffaflık ilkesi tanımlarına işaret etmeden önce açıklık ilkesinin ortaya çıkışına ve bu ilkelerin dönemsel olarak kazandığı anlamlara yer verilecektir.

Şeffaflık ve açıklık kavramlarının idari sistemi açıklamak için kullanmaları 20. yüzyıla dayanmaktadır. Eken'e (2005) göre açıklık ve şeffaflık kavramları görünenin arkasındakileri görme ve anlama eğilimini açıklamak için kullanılmaktadır. Özay (2002:663) ise açıklık kavramı yerine idarenin karar alma toplantılarının aleni olarak yapılmasını ifade eden günışı̆̆ kavramını kullanmaktadır.

Şeffaflık ve açıklık ilkelerinin aksine gizlilik ilkesi idarenin bilgileri kendisine saklamasını gerekli görür. İdarenin bilgileri saklamasının nedeni, idarenin halk ve halk temsilcilerine karşı kendi gücünü arttırma isteğidir. $\mathrm{Bu}$ durumda gizlilik yöneten yönetilen arasındaki güvensizlik durumunu arttırarak; daha anti-demokratik bir yönetim ortamı yaratacaktır. Bu durum idarenin tarafsızlık ilkesiyle doğrudan bağlantılı olarak uygulanmaktadır (Eken, 1994:36-37). Açıklık taleplerinin ortaya çıkışı devletin müdahaleci politikalarındaki artışla bağlantılıdır. Sosyal devlet düzeni ile devletin ekonomik ve toplumsal hayata müdahalesi ile zirve yapmaktadır. Toplumun eğitim ve kültür düzeyindeki değişimler, kamu yönetiminin işleyişinde bask1 sonucu yönetimde hâkim paradigma olan gizlilik ilkesinden vazgeçilerek açıklık ilkesine geçişe zemin hazırlamıştır (Eken, 1994:41).

Al'a (2007:230-231) göre bilgi toplumu sonrası, demokratik değerlerin güçlenmesi ve bilgiye erişim maliyetinin hem ucuz hem de kolay olması nedeniyle idarenin tarafsızlı̆̆ ilkesi ile bağlantılı olan gizlilik ilkesi uygulanamaz hale gelmiştir. Bu durumda gizlilik ilkesi yerini açıklık ve şeffaflık ilkelerine bırakmıştır. Gizlilik sanayi toplumunda yer alan bir paradigma olarak ele alınırken, açıklık ilkesi bilgi toplumunda egemen paradigma haline gelmiştir. Açıklık ilkesinin etki alanı; siyasal, idari ve ekonomik sistemlerde gözlenmektedir. Açıklık ilkesi kamusal alanda politika yapım sürecinde idarenin karar alma sürecinde kullanılan bilgileri ve araçları vatandaşlara açık hale getirmesi olarak uygulanırken; özel kesimde şirketlerin kendileriyle ilgili bilgileri hem müşterilerine hem de çalışanlarına açmaları şeklinde uygulanmaktadır.

Yukarıdaki açıklamalar ışı̆̆ında, idarenin işlemlerine muhatap olan kişilerin idari işlemler sonucu ortaya çıkan kararlara müdahaleler ve tarafların uğradığı zararlar çerçevesinde; söz konusu idari kararların yapılması sürecinde başvurulan işlemlerin ve eylemlerin dayandığı sebepler ve kullanılan araçlar konusunda bilgilenme taleplerinin artması sonucu idari karar süreçlerinde açıklık taleplerinin ortaya çıktığı söylenebilir. İlaveten, paradigma değişimi sonucu şeffaflık ve açıklık ilkelerinin uygulama alanının uluslararası zemine taşındığı gözlenmektedir. Nitekim şeffaflık ve açıklık ilkelerinin denetiminde "Uluslararası Şeffaflık Örgütü"nün kurulması, OECD raporunun iyi yönetişimin ilkelerinden biri olarak açıklık ilkesini tanımlaması ve AB'nin bu konu hakkında yayınlanmış raporları bu tespiti desteklemektedir.

Şeffaflık ve açıklık ilkelerinin kurumsallaşarak "evrensel" bir uygulama zeminine kavuşması; küreselleşme düzeni ile olmuştur. Küreselleşmeyle birlikte yönetimden yönetişime, ulusal kuruluşlardan uluslararası kuruluşlara doğru bir değişim yaşanmaktadır. Bu durumun şeffaflık ve açıklık ilkelerine yansıması; söz konusu ilkelerin denetiminde OECD raporlarında iyi yönetişimin ilkelerinden biri olarak şeffaflık ve açıklık ilkelerinin tanımlarının yeniden yapılması şeklindedir. Ayrıca Avrupa Birliği; şeffaflık tanımlarının oluşturulmasına katkı sağlayan bir diğer kurum olarak gözlenmektedir.

Küresel düzenin getirdiği şeffaflık ve açıklık ilkelerine bakıldığında, kamu yönetimleri için Avrupa İlkeleri başlıklı SIGMA raporunda (1999:11) "Açıklık ve Şeffaflı" ilkelerinin tanımları yer almaktadır. Buna göre açıklık idarenin dış denetimi için kullanılırken, şeffaflık idarenin gözetim, inceleme ve denetim süreçlerinde olduğu gibi değerlendirilmesi olarak ifade edilmektedir. 
OECD raporlarında şeffaflık kavramı kurumsal iyi yönetişim ilkeleri içerisinde yer almaktadır. Özellikle çok uluslu şirketlerin uygulaması için şeffaflık ilkesi (OECD, 2015:6);

"Kamuyu aydınlatma ve şeffaflık; kamuya yapılacak açıklamaların temel alanlarını belirlemektedir, örneğin; finansal ve faaliyet sonuçları, şirket hedefleri, büyük pay sahipliği, ücretlendirme, ilişsili taraf işlemleri, risk faktörleri ve yönetim kurulu üyeleri. Bu bölümdeki yeni konular şirketlerin gönüllülük esasına dayalı olarak, örneğin yönetim raporlarına, dâhil edebilecekleri finansal olmayan bilgilere iliş̧kin yeni eğilimlerin tanınmasını içermektedir"

$\mathrm{Bu}$ tanımda öne çıkan unsurlar; kamuyu aydınlatma işlevini yerine getirmek için şirketler için oluşturulmuş ilkeler çerçevesinde iç ve dış paydaşlarla "gönüllülük esasına dayalı olarak" yeni durumlara uyum sağlama olarak ele alınmaktadır. Öte yandan, Kamu Yönetimi ilkesi olarak şeffaflık ve açıklık ilkeleri OECD (2012:6) tarafından şöyle ifade edilmektedir;

"Düzenlemelerin kamu yararına hizmet etmesi ve düzenlemelerden etkilenen tarafların meşru ihtiyaçlarının karşılanması amacıyla, şeffaf ve katılımcı karar süreçlerini kapsayan açık devlet prensiplerine uyulmalıdır. Bu kapsamda, kamuoyunun düzenleme taslaklarının hazırlanması ve destekleyici analizlerin kalitesinin artırllmasına yönelik süreçlere iştirak etmelerini sağlayacak firsatlar yaratılması gerekir. Hükümetler, düzenlemelerin açık ve anlaşılır olmasını sağlayarak, paydaşların hak ve yükümlüklerini kolayca anlamalarını sağlamalıdır"

Kamu yönetimi ilkesi olarak ele alınan şeffaflık ve açıklık ilkeleri ise kamu yararı ve meşru ihtiyaçların giderilmesini gerçekleştirmeyi merkeze alan katılımcı ve şeffaf süreçlere; açık devlet prensiplerine bağl1lı̆a referans verir. Kamuoyu desteğini, süreçlere ve raporlara erişimi, katılımı, analizlerin kalitesinin arttırılması için önemli süreçler olarak ortaya koyar.

Şeffaflık ve açıklık ilkeleri kamu politikalarının karar alma sürecinde yer alan taraflardan biri olarak idarenin tanımlanmasında kullanılmaktadır. Güran (1982:102), yönetimin açıklığı kavramını idarenin "tek yanlı" karar alma yetkisini kullanırken "kapalılığın aralanması", karar alma sürecinin saydamlığa kavuşturulması; Duran (1998:29) ise karar alma sürecinde kullanılan bilgi ve belgelerin ilgililerin erişimine açılması olarak tanımlamaktadır.

Başka bir tanımda Eken (1994:39) tarafindan "şeffaf yönetim", Duran (1998) tarafindan "açıklık" ve Özay (2002) tarafindan da "günışığında yönetim" kavramları ile tanımlanan yönetim biçimi gizli ve dışa kapalı yönetim sistemine alternatif bir model olarak tanımlanmaktadır. Bu modelde yönetim ve toplum arasındaki mesafenin azaltılarak yönetimin toplumsal duyarlılığının arttırılması amaçlanmaktadır (Eken, 2005:116). İdarenin bilgileri kendisine saklamasının nedeni, idarenin halk ve halk temsilcilerine karşı kendi gücünü arttırma isteğidir. Bu durumda gizlilik, yöneten yönetilen arasındaki güvensizlik durumunu arttırarak daha antidemokratik bir yönetim ortamı yaratacaktır. Söz konusu ilkeler, idarenin tarafsızlık ilkesiyle de bağlantılı olarak uygulanmaktadır (Eken, 1994:36-37).

Açıklık ilkesi tanım olarak, idarenin otoriter tutumunun ve sınırlı katılımın azaltılarak halkın etkilerine açık bir yönetimin inşa edilmesidir (Örnek, 1992:38). Bu ilke sadece karar alma sürecinde tarafların bilgilendirilmesinden ibaret değildir. Karar alma süreci sonrası alınan kararlardan ilgili kişilerin haberdar edilmesini de kapsamaktadır. Böylece kişiler isterlerse açıklık ilkesinden yararlanarak haklarında alınan kararları değiştirme imkânına da kavuşmuş olacaklardır (Eryılmaz, 1993:102).

Bu tanımlar yönetim bilimi ve siyaset bilimi kavramlarından hareketle oluşturulmuştur. Güran'ın (1982) ve Eryılmaz'ın (1993) tanımı şeffaflık ve açıklık ilkelerini, idarenin tek yanlı idari işlemleri ile sınırlarken; Eken (1994), bir yönetim modeli olarak tanımlayarak toplum yönetim mesafesini azaltacak bir araç olarak şeffaflık ve açıklık ilkelerinin uygulama ve etki alanını genişletmektedir. Bu tanımlar yönetim bilimleri ve siyaset biliminin kavramlarına dayanmaktadır. Bu tanımlara ek olarak Şeffaflık ve açıklık ilkeleri maliye disiplini içinde de tanımlanmaktadır.

Açıklık ilkesi, maliye disiplini içinde satın alımlarla ve bütçeyle ilgili olarak tanımlanmaktadır. Satın almalarla ilgili olarak açıklık ilkesi; kamu alımlarını ifade eden ihale süreçlerinde gerek katılımcı olarak sürece dâhil olan gerekse ihale süreciyle ilgili olanların görsel ve işitsel araçlar ile sunulan bilgilere erişimini anlatır. Bütçeyle bağlantılı olarak açıklık ilkesi ise kamu hizmetlerinin en etkili ve verimli bir şekilde gerçekleştirilmesi için kaynak kullanımı ve kamu finansmanını düzenleyen bir araç olarak bütçenin herkes tarafından kolaylıkla anlaşılabilir olmasını ifade eder (Parlak, 2011:3). 
Maliye disiplini çerçevesinde yapılan tanım, yönetim bilimi ve siyaset bilimi tanımları ile büyük ölçüde kesişmekle birlikte, verimli ve etkin yönetimin tesisi için anlaşılırlık ölçütüne referans vermekte, kavramın alanını satın alımlar ve bütçe süreçleri, ihale süreçleriyle sınırlamaktadır. Bu yönüyle diğer tanımlardan ayrıldığı söylenebilir.

Dijital teknolojilerin ivme kazanmasıyla birlikte şeffaflık ve açıklık ilkelerinin anlamları yeniden sorgulanmaya başlamış, özellikle teknolojik dönüşümün söz konusu ilkelerle ilişkisi alan yazında geniş bir tartışma alanı bulmuştur. Bu tartışmalar; ülke yönetimlerinin yeniden yapılandırılması, düzenleme rejimlerinde yeni araçların ve yeni ilkelerin kullanılması, Endüstri 4.0 dönüşümü sonucu devletlerin kamu hizmeti sunma ve üretici konumdan çekilme durumu dolayısıyla bir aktör politika tasarlayıcı, yapıcı, uygulayıcı işlevleriyle ilgili hesap verici konumlarının yeniden inşası ve sorgulanması şeklindedir.

Yeni gelinen durumda vatandaşlar devlet karşısında güçlenirken, ulusal ve ulus-üstï sivil örgütler, piyasa mekanizmasının aktörleri ve sosyal medya aracılığı ile süreci yönlendiren "influencer" grupları alan yazında yerini almaktadır. Bu koşullarda devlet düzenlerinin yeni duruma gösterebileceği reflekse ilişkin çeşitli senaryolarda yine alan yazında görülmektedir. Bu hususta özellikle Vesnic vd. (2019)'in ülke yönetimine dair dörtlü matrisinde yer alan iki senaryodan bahsedilebilir. İlk olarak, vatandaşların doğruca kamu hizmeti üreticisi konumuna geldiği, kişisel dijital platformlar ve girişimler aracılığıyla süreci kurgulayıp yönettiği " $D I Y$ Demokrasi" (Do-it-yourself Democracy) modelidir (Lee, 2014:2). İkinci olarak, devletin düzenleme işlevinin ivme kazandığı, kişisel verilerin bilgisiyle sürecin her aşamasını standartlarla, ilkelerle kontrol altına aldığı, potansiyel tehdit durumlarının vatandaş lehine önceden önleyecek tedbirlerin alındığı düzenleyici yönetim (regulactocracy) modelidir (Vesnic, 2019:1).

$\mathrm{Bu}$ senaryolar devlet yönetim tasarımları olarak tartışılmakla birlikte, politika tasarımı, yapımı ve uygulaması süreçlerinin tarafları olarak; devlet, vatandaş, sivil örgütler, piyasa ve influencerların birbirleri ile ve sistemle ilişkileriyle doğrudan bağlantılı olan şeffaflık ve açıklık ilkeleri ile ilgili olarak da yorumlanabilir (World Economic Forum, 2018). Bu bağlamda açık yönetim ile açık yönetimle doğrudan ilişkili yönetişim, katılımcı demokrasi, stratejik yönetim, e-devlet ve e-demokrasi, açık bütçe yönetimi ve süreçleri, blokzinciri teknolojisiyle veri depolama ve dijital ödeme sistemleri, politika laboratuvarları (policy labs) gibi uygulamalar söz konusu ilkeleri değerlendirmek için önemli referanslar sunmaktadır (World Economic Forum, 2020).

\section{E-KATILIMIN KAVRAMSAL BOYUTU}

E-katılım kavramı, bilgi ve iletişim teknolojilerindeki gelişmelerin siyaset bilimi ve yönetim bilimi alanlarına etkisi sonrası, geleneksel "katılım" kavramının yeni bir formu olarak ele alınabilir. Akademik çalışmalarda ekatılım kavramı basitçe vatandaşların bilgi ve iletişim teknolojileri araçlarıyla karar alma aşamalarına ve kamu hizmetleri erişiminin sağlanması olarak tanımlanmaktadır (Macintosh, 2004; Saebø vd., 2008; Medaglia, 2012). Diğer bir tanımlama biçimi ise politika yapımı sürecinin tasarımı, karar alma süreçleri ve karar süreçleri kapsamında ele alınmaktadır. Ayrıca, "e-demokrasi" ve "e-devlet" kavramları ile bağlantılı olarak açıklanmaktadır (Welch, 2012). Dolayısıyla e-katılım kavramı hem e-demokrasi hem de e-devlet alanı ile bağlantılı olarak iki açılı bir okumaya tabi tutulabilir. E-demokrasi kapsamında özellikle sivil katılım süreçleri, vatandaşların diğer aktörlerle karşılıklı etkileşimleri, karar alma süreçleriyle ilgili bilgiye erişim ekseninde incelendiği gözlenmiştir. Macintosh'a (2004) göre "e-oylama", e-demokrasi içerinde ele alınabilirken; e-katılım kavramı, e-demokrasi kapsamında ele alınamaz. Öte yandan Reddick ve Norris (2013) e-katılım ve e-demokrasi kavramını birbirinin yerine kullanmıştır. Saebø vd.'ne (2008) göre e-katılım kavramı, bilgi ve iletişim teknolojileri aracılığı ile toplumsal aktivitelere katılım olarak ele alınabilir. Katılım sürecinde temel vurgu; vatandaşlar, kamu yöneticileri ve poltikacılar arası etkileşim üzerinedir. Bu bilgi ışı̆̆ında alan yazında edemokrasi ve e-katılımın sınırlarının net olmadığı ifade edilebilir.

E-devlet kapsamında e-katılım ilişkisi, kamu hizmetlerinin üretilmesi ve kamu hizmetlerine erişim kapsamında açıklanmaktadır. E-devlet, genel tanım olarak kamu hizmetlerinin sunumunda teknoloji kullanımı olarak tanımlanmaktadır (Yıldız, 2007). E-devlet ile diğer araştırma alanları arasındaki ayrım net değildir (Yıldız, 2013). Son dönem çalışmalarda, e-devlet alanı, yönetimde bilgi ve iletişim teknolojilerinin rolüne odaklanan "dijital devlet" ve "dijital yönetişim" kavramlarına doğru geçiş göstermektedir (Gil-Garcia vd.. 2018; Arias ve Maçada, 2018). Bu geçiş ile özellikle e-devlet ve e-katılım arasındaki kesişim alanının genişlediği söylenebilir.

E-katılımın hem teorik boyutunun geliştirilmesi, hem de ölçülebilmesi ve somut değişkenlerle açıklanabilmesi için farklı düzeylerde ve farklı alanlarda e-katılım uygulamalarını konu alan araştırmaların arttırılmasının gerekliliği alan-yazında vurgulanmaktadır (Gibson vd., 2005). Farklı düzeylerde karşılaşılan e-katılım 
uygulamaları; merkezi yönetim düzeyinde (Saylam, 2020) yerel yönetim düzeyinde (Karkın ve Çalhan, 2011). Farkl1 alanlarda e-katılım uygulamaları ise yerel yönetim hizmetleri (Karkın ve Çalhan 2012), güvenlik hizmetleri (Yıldız ve Ekmekçioğlu, 2021) şeklinde ifade edilebilir.

\section{KAMU POLITIKALARINDA ŞEFFAFLIK VE AÇIKLIK ILLKELERINE E-KATILIMIN ETKİSI}

Şeffaflık ve açıklık ilkelerinin kamu politikaları çalışmalarındaki anlamı incelendiğinde, söz konusu ilkelerinin açık kamu politikaları (open public policy) olarak adlandırıldığı görülmektedir. Açık kamu politikaları, politika yapımı sürecini oluşturan önemli politika kararları ve eylemlerinde yer alan tüm taraflar için şeffaflığın olduğu bir süreç olarak tanımlanır (Bertot vd., 2010; Rabina, 2011; Meijer, 2013). Hem Bertot vd.'nin (2010), hem de Ferro vd.'nin (2013) çalışmalarına göre kamu politikalarında açıklığın önemli bir boyutunu dijital olarak etkin şeffaflık oluşturmaktadır. Şeffaflık ilkesi ise Bertot vd. (2010) ile Meijer'in (2013) çalışmalarında; kamu politikasıyla ilgili kararlar hakkında politika sürecinde yer alan ya da kararlardan etkilenen tüm tarafların kararla ilgili bilgilendirilmesi olarak tanımlanır.

Harrison ve Sayogo (2014) tarafından yapılan çalışmada şeffaflık, kamu politikası sürecinde bilgi farkındalı̆̆ 1 ve erişim sağlayan bir ilke olarak tanımlanmaktadır. Açık kamu politikaları konusunda yapılan çalışmalar, politika yapımı sürecinde karar alıcıların politika tasarımında kullandıkları araçları ve bu araçları nasıl ve neden kullandıklarına ilişkin bilgileri ilgili taraflar ve herkesle paylaşarak, erişime açarak şeffaflık ilkesinin hesap verilebilirlik boyutunu arttırmayı amaçlamaktadır. Bu tanımda politika tasarım sürecinde vatandaşların ve hükümetin ilişkisine odaklanılmaktadır. Vatandaşların politika tasarım süreci hakkında bilgilendirilerek, sivil katılım kanallarının desteklenmesi ve vatandaş ile politika yapıcı arasında diyaloğun desteklenmesi hedeflenmektedir (Noveck, 2010; Irani vd., 2008).

Alan yazında başka çalışmalarda şeffaflık ilkesi, politika tasarımında hesap verilebilirlik, güvenilirlik kavramlarını da kapsar. Politikaların etkililiğini ve tekil yararlanıcıların faydalarını arttırarak tüm yararlanıcı tarafların faydasını dolayısıyla kolektif refahı arttırır (Lee ve Kwak, 2012; Medaglia, 2012).

İlk tanımda politika sürecinin tasarımında içsel olarak tarafların bilgiye erişiminin arttırılması ve tarafların önemli politika alanlarında katılma ve eylemde bulunmaları ile bağlantılıdır. İkinci tanımlama biçimi ise daha çok politikaların etkinliğinin arttırılması ve dışsal etkiler sonucu yararlanıcıların faydalarındaki artışın kolektif faydaya katkısı üzerine odaklanmaktadır. Kamu politikaları çalışmalarında şeffaflık ve açıklık ilkelerinin tanımlanma biçimleri bu şekilde açıklanabilir. Daha önce de belirtildiği gibi çalışmamız şeffaflık ve açıklık ilkelerini e-katılımın içsel etkileriyle açıklayan çalışmalarla ilgilidir.

Bilgi ve iletişim teknolojilerinin yükselişi, bilgi politikaları, e-devlet, e-katılım çalışmaları; kamu politikalarında açıklı ve şeffaflık ilkelerinin önemini akademik tartışmaların gündemine yerleşmiştir. Alan yazında, politika yapıcıların yaygın bir şekilde dijital teknolojileri kullanmasının, politika geliştirme sürecinde halkın bilgiye erişimini ve politika yapım süreçlerinde açıklık ve şeffaflığı arttırdığını gösteren çalışmalar mevcuttur (Nam, 2012; Larsson ve Grönlund, 2014).

Dijital olanaklara dayalı şeffaflık, kamu politikaları süreçlerinde açıklık ve şeffaflık ilkelerinin uygulanabilmesi için önemli bir boyut olarak değerlendirilebilir (Bertot vd., 2010; Ferro vd., 2013). Şeffaflık tanımının kurucu unsuru, tüm tarafların kamu politikalarıyla ilgili süreçlerde ya da politikalarla ilgi alınan herhangi bir karar hakkında bilgilendirilmesi ve süreçte yer almalarıdır (Bertot vd., 2010; Meijer, 2013). Dolayısıyla kamu politikalarında şeffaflık ve açıklık ilkeleri, kamu politikası yapımı, karar alma, uygulama ve değerlendirme süreçleriyle ilgili bilgiye erişim ve farkındalık sağlamaktadır (Harrison ve Sayogo, 2014).

Mevcut alan yazında açık kamu politikaları çalışmaları; daha hesap verebilir, açık ve şeffaf kamu politikalarının nasıl oluşturulacağını, politika yapıcıların ve karar vericilerin mevcut politika tasarımlarını nasıl ve neden herkesin erişimine açılacağını araştırır (Harrison ve Sayogo, 2014). İçsel olarak şeffaflığın sağlanması ve şeffaflığın içselleştirilmesi; politika tasarım ve yapım süreçlerinde hükümet içinde ve dışında "sivil katılımın" (civic participation) güçlendirilmesi ve diğer katılım yollarının teşviki için politika yapıcılar ve karar vericilerle diyalog içinde hareket etmekle mümkün olmaktadır. Şeffaflık ve açıklık ilkelerini devlet vatandaş ilişkilerine odaklanarak politika tasarımında kullanılan araçlar ve siyasalarla ilgili konular hakkında tüm tarafların süreçler hakkında bilgi sahibi olarak vatandaş devlet arası diyalog ve sivil kanalların desteklenmesi; şeffaflık ve açıklık ilkelerinin siyasa yapım sürecine içsel etkisi olarak adlandırılmaktadır (Bélanger ve Carter, 2008; Sæbø vd., 2008). 
Şeffaflık ve açıklık ilkelerinin siyasa yapım sürecine içsel etkileri, e-katılım uygulamasının yaygınlaşmasıyla ortaya çıkan "teknoloji-ortamlı etkileşim" ile açıklanmaktadır (Gil-Garcia ve Martinez-Moyana, 2007). Bu açıklamada e-katılım, bir yanıyla sivil toplum ile resmi politikaları, öte yandan sivil toplumla kamu yönetimleri arasındaki teknoloji-ortamlı etkileşimi kapsar. Dolayısıyla e-katılım, e-yönetim ve e-yönetişim katılımı ile yakından ilgilidir. Aynı çalışmada, iyi tasarlanmış bir e-katılım çerçevesi; hükümet politikalarına, programlarına, bütçelerine, hukuk ve düzenlemelerine, danışma ve karar alma araç ve mekanizmalarına çevrimiçi erişilebilir olmalıdır (Gil-Garcia ve Martinez-Moyana, 2007).

Bilgi iletişim teknolojilerinin gelişimi, vatandaşların bilgi edinmelerini, oy yoluyla vatandaşların siyasal görüşlerini ifade etmelerini sağlar. Böylece etkili, dürüst toplum ve hükümetin teşviki için aktif vatandaşlığ 1 son gelişen teknolojilerle destekler, bilgiye erişimin artışını ve katılıma erişilebilirliği sağlar (Medaglia, 2012). Bir yanıyla bilgi ve iletişim teknolojileri, vatandaş katılımının artması için büyük bir potansiyele sahiptir (Lunat, 2008; Sapsed ve Salter, 2004). Başka çalışmalarda bilgi ve iletişim teknolojileri yoluyla katılımın karar alma sürecine etkileri; halkların algılarını, sorunsalların belirlenmesini, kamu davranışlarının etkilerini potansiyel olarak yanıltıcı şekilde şekillendirmede önemli bir etkiye sahiptir (Wehn ve Evers, 2015; Susha ve Grönlund, 2012; Barrios vd., 2016).

E-katılım ile sivil katılımın, demokrasi seviyesinin ve yönetişimin artmasının ötesinde; sosyal kontrol ve gündelik hayatı denetleme riski de toplumun karşılaşacağı bir sorun olarak karşımıza çıkmaktadır (Bauman ve Lyon, 2013). Öte yandan, e-katılımın açıklık ve şeffaflık ilkesine etkisini şöyle açıklanabilir: Devletler dijital teknoloji ile elde ettikleri bilgileri; gelişen sivil katılım kanallarını, kendi yararlarına kullanmaktadır. Nüfusları denetlemek ve kontrol altında tutmak, toplumsal açıdan uygunsuzlukları dışlamak ve toplumsal düzeni onarmak ve yeniden üretmek için teknolojileri kullanırlar (Bigo, 2002).

Dijital teknolojilerin kamu politikalarına katılımı arttırmada, kamusal katılımı ve mevcut siyasal sistemde temsili cazip hale getirmede etkili bir araç olduğu yönünde görüşler yer almaktadır. Yeni iletişim teknolojileri siyasal sistem içindeki temsiliyeti arttırıcı bir etki yaratır (Jho ve Song, 2015), toplumsal ve sivil ağ hizmetleri siyasal katılımın alanını genişleterek hem işbirlikçi hem de etkileşimli bir ilişki biçimi oluşturur (Fraser ve Dutta, 2008).

Alan yazındaki çalışmalar değerlendirildiğinde kamu politikalarında e-katılımın şeffaflık ve açıklık ilkesine iki boyutlu etkide bulunduğu gözlenmektedir. Bunlardan biri e-katılımla birlikte bilgiye erişim artmış, taraflar arasında edinilen bilgi; şeffaflık ve açıklık ilkelerinin uygulanması için taraflar arası diyalogun ve sivil katılım kanallarının desteklendiği bir vatandaş-devlet ilişkisini sağlamıştır. İkinci olarak, e-katılımla birlikte artan bilgi, yönetimin beklentileri ve yararına kullanılarak halkların algısının ve kamusal davranışlarının yönlendirildiği, toplumsal kontrol ve gündelik hayatın denetim altına alındığ 1 bir ilişki biçiminin üretilmesine zemin hazırlamıştır.

\section{SONUÇ}

$\mathrm{Bu}$ çalışma, kamu politikalarında şeffaflık ve açıklık ilkelerine e-katılımın etkisini inceleyerek, söz konusu ilkelerin farklılaşan tanımlarını tespit etmiştir. İlk olarak, Şeffaflık, katılım ve açıklık ilkelerinin kavramsal temelleri açıklanmıştır. Kavramsal çerçeve oluşturulurken hem alan yazındaki çalışmalar hem de ulus-üstü kurumların raporlarındaki tanımlardan yararlanılmıştır. Çalışmanın temel savı, kamu politikalarında şeffaflık ve açıklık ilkelerinin süreç içerisinde kavramsal içeriklerinin ve anlamlarının değişime uğradığıdır. Söz konusu savı destekleyecek şekilde alan-yazında ve raporlarda, kamu politikalarında şeffaflık ve açıklık ilkelerinin ekatılım ile ilişkisi araştırıldığında, şeffaflık ve açıklık ilkelerinin üç farklı tanımlarına ulaşılmıştır.

İlk olarak temel hakların gelişim dönemi ile örtüşen, vatandaşların kamusal süreçlerle ilgili bilgi alma taleplerinin arttığı 20. yüzyıldaki tanımlama biçimidir. Bu tanımda vatandaşların kamusal süreçler hakkında bilgi alma talebi, şeffaflık ve açıklık ilkesini tanımlamak için yeterli görülmüştür (Al, 2007:230-231). Bu dönemde devlet tek yanlı karar alma mekanizmalarıyla politika tasarımı ve karar alıcı konumunu sürdürürken; sürecin inşasına katkı yapan, yönlendiren kamu olgusundan ziyade "tek yönlü olarak devlet tarafindan, devletin izin verdiği ölçüde" (Eken, 1994:36-37) kamunun bilgiye erişimi söz konusudur.

İkinci tanımlama biçiminde sosyal devlet düzeninde, devletin müdahale alanını genişlettiği dönemde, şeffaflık ve açıklık tanımı; sürece katılım talebi olarak adlandırılmaktadır. Bu tanımda tarafların hem süreçten haberdar olma hem de politika yapım sürecinin tasarımı aşamasını izleme (Örnek, 1992:38) ve sonuçların takibini sağlama (Eryılmaz, 1993:102), şeffaf yönetim ve açıklık ilklerinin kurucu unsurları olarak görülmektedir. Bu dönemde bilgiye erişim ve politika tasarım sürecinde taraflar doğrudan yer almamakla birlikte, tarafların 
meydana gelen kararların sonuçlarından etkilendikleri ve politika yapım süreçleri üzerinde kısmi olarak etkili oldukları görülmektedir. Diğer bir ifadeyle taraflar, politika yapma ve karar alma sürecinin başlangıcına dâhil olmamakla birlikte, süreç izleme ve sonuçların takibi açısından aktif bir rol üstlenmişlerdir.

Üçüncü tanımlama biçimi ise bilgi toplumuna geçiş paradigması ile ortaya çıkan bilgi ve iletişim teknolojilerinin gelişimi sonucu e-katılımın etkisinde olan şeffaflık ve açıklık ilkesidir. Buna göre kamu politikaları sonucu alınan kararların sonuçlarından etkilenen ya da ilgili olan tüm tarafların süreçten haberdar olması, sürece sivil katılım kanallarıyla dâhil olması, alınan kararın sonuçlarını ulusal ve uluslararası seviyede denetleyerek (SIGMA, 1999:11) değiştirme talebinde bulunması açıklık ve şeffaflık ilkesinin tanımın oluşturur. Bu tanımlama biçiminde önemli nokta kamu politikalarının tasarımından, yapımına, karar almadan uygulamaya tüm süreçten tarafların haberdar olması, süreci izleyerek sonuçların takibini yapması, ulusal ve ulus-üstü katılım kanalları yoluyla sonuçlara müdahale edip değiştirebilir olması (OECD, 2012:6) bu tanımlama biçiminin temel bileşenleridir.

E-katılım; vatandaşların bilgi ve iletişim teknolojileri araçlarıyla karar alma aşamalarına ve kamu hizmetlerine erişimleridir (Macintosh, 2004; Saebø vd., 2008; Medaglia, 2012). Diğer bir tanımda ise politika yapımı sürecinin tasarımı, karar alma süreçleri ve takibi kapsamında ele alınmaktadır. Ayrıca, e-demokrasi ve e-devlet kavramları ile bağlantılı olarak açıklanmaktadır (Welch, 2012). Bu bilgi 1şığında; e-katılım kavramı hem "edemokrasi", hem de "e-devlet" alanı ile kesişim bölgelerinin olduğu söylenebilir. E-devlet kavramından, yönetimde bilgi iletişim teknolojilerinin etkisini anlatan "dijital devlet" ve "dijital yönetişim" kavramlarına geçiş; e-katılım ve e-devletin kesişim alanını genişletmektedir.

Alan-yazında yer alan kamu politikalarında şeffaflık ve açıklık ilkelerini e-katılımın etkileriyle açıklayan çalışmalar incelendiğinde, tarafların ve kamu politikaları sonucu alınan kararların sonuçlarından etkilenen kişilerin karar alıcılarla ilişkisi; açıklık ve şeffaflık ilkeleri çerçevesinde iki şekilde değerlendirilebilir.

İlk olarak e-katılım ile bilgiye erişim artmış, politika yapım sürecinde bilgiye erişim ile birlikte şeffaf yönetim için gerekli etkili toplum ve dürüst hükümet uygulamalarının "teşviki" için gerekli aktif vatandaşlık ve sivil katılım kanalları çalıştırılmıştır (Lunat, 2008; Sapsed ve Salter, 2004). Bu durumda siyasal katılımın alanı genişletilerek taraflar arası iş birliği ve etkileşim için gerekli ortam yaratılmıştır. Bunun doğal sonucu olarak siyasal sistem içinde tarafların temsiliyeti artmıştır. İkinci olarak e-katılımla birlikte bilgiye erişim artmış, yönetimler edindikleri bilgileri; halkların algılarını, kamusal sorunlarını ve davranışlarını yanıltıcı bir biçimde şekillendirerek toplumsal kontrol ve denetim (Bauman ve Lyon, 2013) için kendi lehlerine kullanmaktadırlar. Böylece sosyal kontrolü sağlayarak toplumsal düzeni yeniden üretmektedirler.

Son gelinen noktada açık yönetim ve şeffaflı̆̆ın uygulanması için yönetim içi ve yönetim dışı şeffaflığın bilişim teknolojilerinin etkisiyle arttırılarak ülke yönetimlerinin yeniden yapılandırılmasına yönelik uygulamalar geliştirilmektedir. Alan-yazında Endüstri 4.0 olarak adlandırılan dönüşümle ortaya çıkan, devletlerin kamu hizmeti sunma kapasitelerinin sınırlı oluşu ve özellikle mali olanaklarının yetersiz oluşu, vatandaşları devlet karşısında daha güçlü konuma getirmektedir. Bu koşullarda ortaya çıkan devlet yönetimine ilişkin iki senaryo, "DIY Demokrasi" (Do-it-yourself Democracy) ve Düzenleyici yönetim (regulatocracy) modelleri (Vesnic vd., 2019:1) ve vatandaş yönelimli yönetim olgusu, toplumdaki kültürel dönüşümün sonucu olarak, kurumsal kültürün yenilenmesi ve mevcut kurumların yeni koşullara uyumunun sağlanması için destekleyici ve anlamlı öneriler olarak değerlendirilebilir. Açık yönetim ile açık yönetimle doğrudan ilişkili yönetişim, katılımcı demokrasi, stratejik yönetim, e-devlet ve e-demokrasi, açık bütçe yönetimi ve süreçleri, blokzinciri teknolojisiyle veri depolama ve dijital ödeme sistemleri, politika laboratuvarları (policy labs) bu alandaki uygulamaları oluşturmaktadır.

Söz konusu yeni uygulamalar ve teknolojik gelişimeler birlikte değerlendirildiğinde, alan-yazındaki bilgiler 1şığında, kamu politikalarında şeffaflık ve katılım ilkelerinin e-katılım ile ilişkisi, devlet yönetimlerinin mevcut durumu ve tarafların ilişkileri ile bağlantılı olarak, kamu politikalarında şeffaflık ve açıklık ilkelerinin e-katılım ile ilişkisi iki uç sonucu yaratacağı düşünülebilir. Bunlar;

- Politika yapıcılar ve karar alıcılar ile kararların sonuçlarından etkilenen vatandaşların ve daha önce bahsedilen aktörlerin arasındaki sınırların belirsizleştireceği, bir adım sonrası ortadan kalkacağıdır.

- Politika yapıcılar ve karar alıcılar ile kararların sonuçlarından etkilenen vatandaşların ve daha önce bahsedilen aktörlerin arasındaki sınırların keskinleşeceği, kutuplaşmanın artacağı aşırı düzenleyici ve kontrolcü politika süreçlerinin uygulanacağıdır. 


\section{KAYNAKLAR}

AL, Hamza (2007), Bilgi Toplumu ve Kamu Yönetiminde Paradigma Değiş̧imi, Vadi Yayınları, Ankara.

ARIAS, María Isabel ve MAÇADA, Antônio Carlos Gastaud (2018), "Digital Government for e-Government Service Quality: A Literature Review", Proceedings of the 11th International Conference on Theory and Practice of Electronic Governance, 6-6 April 2018, Galway (IRELAND), ss.7-17.

BARRIOS-O'NEILL, Daniella ve SCHUITEMA, Geertje (2016), “Online Engagement for Sustainable Energy Projects: a Systematic Review and Framework for Integration”, Renewable and Sustainable Energy Review, S.54(C), ss.1611-1621.

BAUMAN, Zygmunt ve LYON, David (2013), Liquid Surveillance: A Conversation, Polity Press, Cambridge.

BELANGER, France ve CARTER, Lemuria (2008), "Trust and Risk in E-Government Adoption", The Journal of Strategic Information Systems, S.17(2), ss.165-176.

BERTOT, John C., JAEGER, Paul T. ve GRIMES, Justin M. (2010), "Using ICT to Create a Culture of Transparency: E-Government and Social Media as Openness and Anti-Corruption Tools for Societies", Government Information Quarterly, S.2(3), ss.264-271.

BIGO, Didier (2002), "Security and Immigration: Towards a Critique of the Governmentality of Unease", Alternatives, S.27(1), ss.63-92.

BRUNSWICKER, Sabine, ALMIRALL, Esteve ve LEE, Melissa Jo (2018), "Transparency in Policy Making: Guiding Citizens Towards Greater Collective Welfare", SSRN Electronic Journal, ss.2-37.

DURAN, Lütfi (1998), “İdari Usul İlkeleri ve Kapsadı̆̆ı Konular”, İdari Usul Kanunu Hazırlığı Uluslararası Sempozyumu Bildiriler Kitabı, Başbakanlık Basımevi, Ankara, ss.31-40.

EKEN, Musa (1994), “Кати Yönetiminde Gizlilik Geleneği ve Açıklı İhtiyacı”, Amme İdaresi Dergisi, S.27(2), ss.25-54.

EKEN, Musa (2005), “Gizlilik Geleneğinden Şeffaf Yönetime Doğru”, Amme İdaresi Dergisi, S.38(1), ss.113130.

ERYILMAZ, Bilal (1993), “Kaти Bürokrasisinin Denetlenmesinde Yeni Gelişmeler”, Amme İdaresi Dergisi, S.26(4), ss.81-106.

FERRO, Enrico, LOUKIS, Euripidis N., CHARALABIDIS, Yannis ve OSELLA, Michelle (2013), "Policy Making 2.0: From Theory to Practice", Government Information Quarterly, S.30(4), ss.359-368.

FRASER, Matthew ve DUTTA, Soumitra (2008), Throwing Sheep in the Boardroom, Cornwall Publishing, Wiley.

GIBSON, Rachel K., LUSOLI, Wainer ve WARD, Stephen (2005), "Online Participation in the UK: Testing a "Contextualised'model of Internet Effects", The British Journal of Politics and International Relations, S.7(4), ss.561-583.

GIL-GARCIA, J. Roman, DAWES, Sharon S. ve PARDO, THERESA A. (2018), "Digital Government and Public Management Research: Finding the Crossroads", Public Management Review, S.20(5), ss.633646.

GIL-GARCIA, J. Roman ve MARTINEZ-MOYANO, Ignacio J (2007), "Understanding the Evolution of Egovernment", Government Information Quarterly, S.24(2), ss.266-290.

GÜRAN, Sait (1982), “Yönetimde Açıklık”, İdare Hukuku ve İlimleri Dergisi: Sarıca'ya Armağan, S.3(1-3), ss.101-112.

HARRISON, Teresa M. ve SAYOGO, Djoko S. (2014), "Transparency, Participation, and Accountability Practices in Open Government: A Comparative Study", Government Information Quarterly, S.31(4), ss.513-525. 
IRANI, Zahir, LOVE, Peter E. D. ve JONES, Stephen (2008), "Learning Lessons from Evaluating Egovernment: Reflective Case Experiences That Support Transformational Government", The Journal of Strategic Information Systems, S.17(2), ss.155-164.

JHO, Whason ve SONG, Kyong J. (2015), "Institutional and Technological Determinants of Civil Eparticipation: Solo or Duet", Government Information Quarterly, S.32(4), ss.488-495.

KARKIN, Naci ve ÇALHAN, Hüseyin Serhan (2011), "Vilayet ve Il Özel İdare Web Sitelerinde E-Katılım Olgusu”, Süleyman Demirel Üniversitesi Sosyal Bilimler Enstitüsü Dergisi, S.1(13), ss.55-80.

KARKIN, Naci ve ÇALHAN, Hüseyin Serhan (2012), “An Interactive e-Participation Model for the Public Administration System in Turkey: SIBIYO”, Ege Academic Review, S.12, ss.105-123.

LEE, Caroline W. (2014), Do-it-yourself Democracy: The Rise of the Public Engagement Industry, Oxford Scholarship Press, Oxford.

LEE, Gwanhoo ve KWAK, Young H. (2012), "An Open Government Maturity Model for Social Media-Based Public Engagement", Government Information Quarterly, S.29(4), ss.492-503.

LUNAT, Ziyaad (2008), "The Internet and the Public Sphere: Evidence from The Civil Society in Developing Countries", The Electronic Journal of Information Systems in Developing Countries, S.35(3), ss.112.

MACINTOSH, Ann (2004), "Characterizing E-Participation in Policy-Making”, Proceedings of the 37th Annual Hawaii International Conference on System Sciences, ss.1-10, https://citeseerx.ist.psu.edu/viewdoc/download?doi=10.1.1.98.6150\&rep=rep1\&type=pdf $\quad$ (Erişim Tarihi: 28.06.2021).

MEDAGLIA, Rony (2012), "E-participation Research: Moving Characterization Forward (2006-2011)", Government Information Quarterly, S.29(3), ss.346-360.

MEIJER, Albert (2013), "Understanding the Complex Dynamics of Transparency", Public Administration Review, S.73(3), ss.429-439.

NAM, Taewoo (2012), "Suggesting Frameworks of Citizen-Sourcing Via Government 2.0", Government Information Quarterly, S.29(1), ss.12-20.

NOVECK, Beth S. (2010), Wiki Government: How Technology Can Make Government Better, Democracy Stronger, and Citizens More Powerful, Brookings Institution Press, Washington DC.

NOVECK, Beth. S. (2015), Smart Citizens, Smarter State: The Technologies of Expertise and the Future of Governing, Harvard University Press, Cambridge.

OECD (2012), "Kamuda İyi Yönetim Ilkeleri”, E-Doküman, http://argudenacademy.org/docs/content/ArgudenYonetisimAkademisi_KamudaIyiYonetisim_WEB.pdf (Erişim Tarihi: 28.06.2020).

OECD (2015), “G/20 OECD Kurumsal Yönetim Illkeleri”, E-Doküman, https://www.oecd.org/daf/ca/CorporateGovernance-Principles-TUR.pdf (Erişim Tarihi: 20.06.2020).

ÖRNEK, Acar (1992), Kamu Yönetimi, Meram Yayıncılık, İstanbul.

ÖZAY, İl Han (2002), Gün Işı̆̆ında Yönetim, Alfa Basım Yayım, İstanbul.

PARLAK, Bekir (2011), “Açıklık İlkesi”, Kamu Yönetimi Sözlüğü, MKM Yayıncı1ık, Bursa.

RABINA, Debbie (2010), Open Government: Collaboration, Transparency, and Participation in Practice (Ed. Daniel Lathrop, Laurel Ruma), O'reilly Sebastopol boks Publisher, Sebastopol (US).

REDDICK, Christopher, and DONALD F. Norris (2013), "E-participation in Local Governments: An Examination of Political-Managerial Support and Impacts", Transforming Government: People, Process and Policy, S.7(4), ss.453-476.

SAEBØ, Oystein, ROSE, Jeremy ve FLAK, Skiftenes L. (2008), "The Shape of Eparticipation: Characterizing an Emerging Research Area", Government Information Quarterly, S.25(3), ss.400-428.

SAPSED, Jonathan ve SALTER, Ammon (2004), "Postcards from the Edge: Local Communities, Global Programs and Boundary Objects", Organization Studies, S.25(9), ss.1515-1534. 
SAYLAM, Ayşegül (2020), “Türk Kamu Yönetiminde Merkezi Düzeyde E-Katıllm: Bakanlıkların Web Siteleri Üzerinden Bir Araştırma”, Pamukkale Üniversitesi Sosyal Bilimler Enstitüsü Dergisi, S.41, ss.23-37.

SIGMA (1999) "European Principles for Public Administration", SIGMA Papers, S.27, http://unpan1.un.org/intradoc/groups/public/documents/nispacee/unpan006804.pdf (Erişim Tarihi: 25.06.2018).

SUSHA, Iryna ve GRONLUND, Åke (2012), "E-participation Research: Systematizing the Field", Government Information Quarterly, S.29(3), ss.373-382.

VESNIC-ALUJEVIC, Lusia, STOERMER, Eckhard, RUDKIN, Jennifer Ellen, SCAPOLO, Fabiana ve KIMBELL, Lucy (2019), The Future of Government 2030+, EUR 29664 EN, Publications Office of the European Union, Luxembourg.

WEHN, Uta ve EVERS, Jaap (2015), "The Social Innovation Potential of ICT-Enabled Citizen Observatories to Increase E-Participation in Local Flood Risk Management", Technology in Society, S.42, ss.187-198.

WELCH, Eric W. (2012), "The Rise of Participative Technologies in Government", Transformational Government Through eGov Practice: Socioeconomic, Cultural, And Technological İssues, ss. 347367.

WORLD ECONOMIC FORUM (2018), White Paper: Agile Governance Reimagining Policy-making in the Fourth Industrial Revolution, World Economic Forum Publisher, Cologny (Switzerland).

WORLD ECONOMIC FORUM (2020), Agile Regulation for the Fourth Industrial Revolution, World Economic Forum Publisher, Cologny (Switzerland).

YILDIZ, Mete (2007), "E-Government Research: Reviewing the Literature, Limitations, and Ways Forward", Government Information Quarterly, S.24(3), ss.646-665.

YILDIZ, Mete (2013), "Big Questions of E-Government Research”, Information Polity, S.17(3-4), ss.343-355.

YILDIZ, Mete ve EKMEKÇİĞLLU, Alper (2021), "Gözetişim: İ̧̧ Güvenlik Süreç ve Hizmetlerine Vatandaşların E-Katılımı”, Kamu Yönetiminde Elektronik Vatandaş Katılımı (Ed. Ayşegül Sağlam), Gazi Kitabevi, Ankara, ss.241-256.

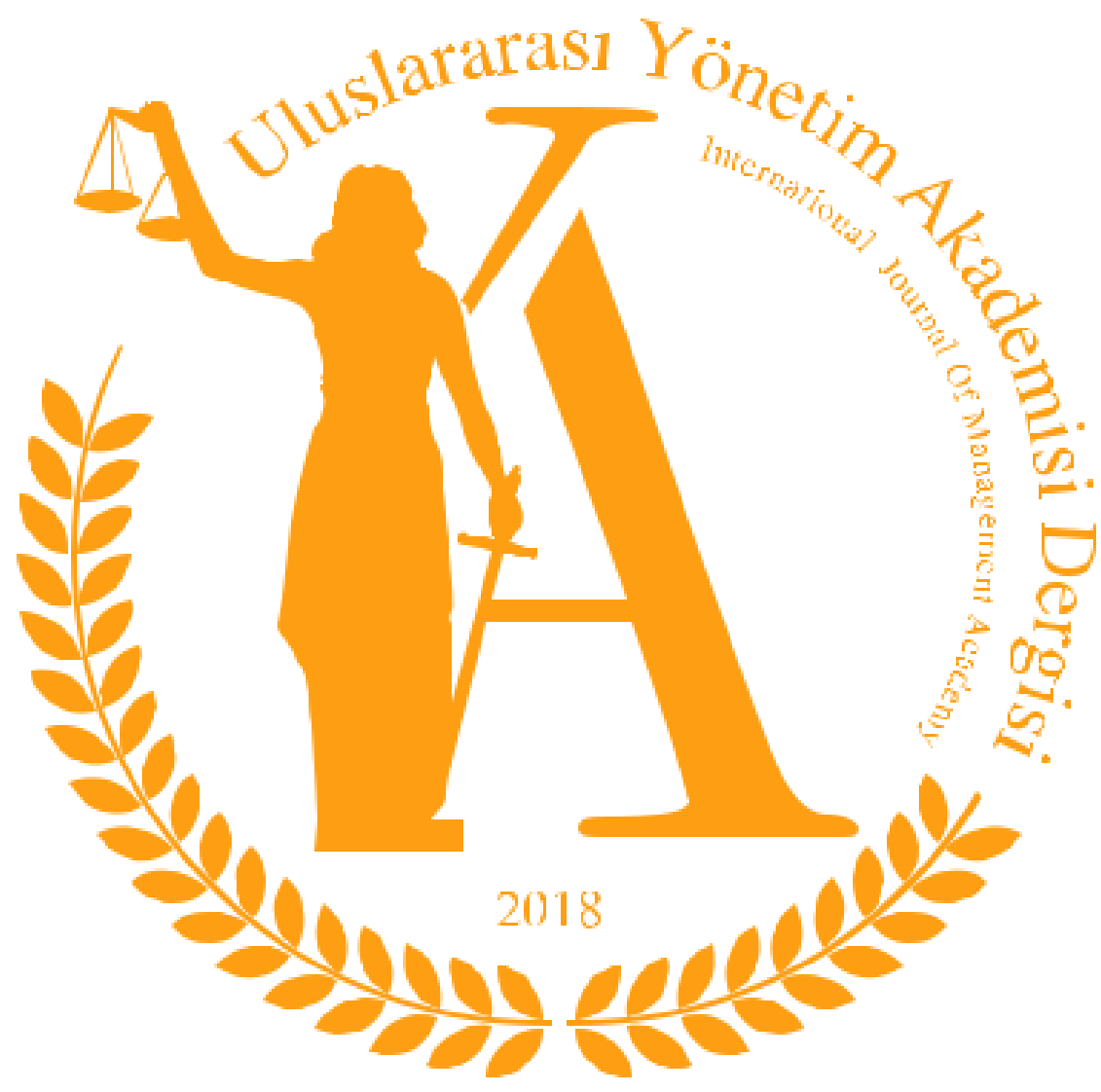

